'Ultimately very difficult to explain,' I conceded, adding: 'Indeed sometimes people are severely disabled when there is no structural disease at all and the process is entirely functional.'

'I thought that most doctors thought that functional dyspnoea was hysterical hyperventilation and therefore regard it lightly,' he replied.

'Yes,' I said, 'but paradoxically when there is cardiac or respiratory impairment they regard breathlessness as a very organic symptom. I have been long concerned that both are over-simplifications.'

'The symtomatologist or disabilitologist might be much better at determining when the critical impairment was the symptom itself and when it was due to the underlying organic disease. He would appreciate the danger of an increase in disability arising solely from a vicious circle of increased disability and increased symptoms, without any deterioration in the underlying organic impairment.'

'That is true,' I said.

'He would also be in a better position to understand that if the perception of symptoms varies from individual to individual then the disability caused by any particular level of organic impairment would also vary from individual to individual. Whilst I am not suggesting that there is no such thing as a malingerer or someone with what used to be called poor moral fibre, no one can be certain of another person's appreciation of symptoms.'

'Agreed. There are layabouts and wimps but do not judge hastily whom they are!'

' $\mathrm{Be}$ that as it may, the perception of severity of impairment is more important than the actual severity.'

'Yes, I am sure a subtle change of approach, recognising this more readily, would substantially reduce much unnecessary disability, which is wrongly attributed directly to mild cardiac, respiratory or musculoskeletal disease.'

'Rather than rehabilitation, habilitation! "Habilitation" is the old word for the provision of initial capital in the mining industry. Shouldn't we provide capital resources from the start to enable those developing chronic illness to continue to lead full lives?'

Surely the cost implications are horrendous, or are they, Prime Minister? Good fuel for another conversation!

Coemgenus

\title{
Stroke in childhood
}

\section{Clinical guidelines for diagnosis, management and rehabilitation}

The National clinical guidelines for stroke and the National sentinel audit together have led to significant improvements in stroke care for adults. Stroke occurring in childhood, although less common, presents serious challenges, which if not well managed, are likely to lead to life-long problems. The Stroke in childhood guidelines are based on the expertise of a multidisciplinary working group and include the views of patients, parents and families. They are designed to bring consistency to the standards of care and rehabilitation for childhood stroke which hitherto has been lacking. The guidelines are mainly consensus based and point to areas where further research and guidance is needed.

The topics covered in the guidelines will make them essential reading for those working in a wide range of disciplines, including primary care, secondary level acute and community paediatrics, tertiary level paediatric neurology and neuro-disability, education and the social services.

The guidelines are accompanied by a booklet for parents and families of children affected by stroke. It will help them to understand what a stroke is, how children should be treated and cared for and where to go for further information and advice.

Published November 2004 ISBN 1860162363

Price: $£ 15.00$ UK, $£ 17.00$ overseas (prices include postage and packing)

AVAILABLE FROM THE ROYAL COLLEGE OF PHYSICIANS 